\title{
Everyday Horizons in Amit Chaudhuri's A Strange and Sublime Address
}

\section{Myriam Bellehigue}

\section{(2) OpenEdition \\ 1 Journals}

Electronic version

URL: https://journals.openedition.org/ces/8320

DOI: $10.4000 /$ ces.8320

ISSN: 2534-6695

\section{Publisher}

SEPC (Société d'études des pays du Commonwealth)

\section{Printed version}

Date of publication: 1 September 2010

Number of pages: 105-116

ISSN: 2270-0633

\section{Electronic reference}

Myriam Bellehigue, "Everyday Horizons in Amit Chaudhuri's A Strange and Sublime Address",

Commonwealth Essays and Studies [Online], 33.1 | 2010, Online since 11 December 2021, connection on 20 January 2022. URL: http://journals.openedition.org/ces/8320 ; DOI: https://doi.org/10.4000/ces. 8320

\section{cc) (†)}

Commonwealth Essays and Studies is licensed under a Licence Creative Commons Attribution - Pas d'Utilisation Commerciale - Pas de Modification 4.0 International. 


\section{Everyday Horizons in Amit Chaudhuri's A Strange and Sublime Address}

Amit Chaudhuri's elliptical and fragmentary prose, far from revealing the familiar as a graspable and reassuring reality, manifests its elusive aspects. His first novel, A Strange and Sublime Address, seems to illustrate how chronicling the everyday through a young boy's screened perspective can be a way of disclosing the strangeness of ordinary life. The sublime referred to in the title could be related to the unexpectedness concealed within the intimate and to its indefinable nature, but also to the constantly renewed wonder it arouses. This article traces the various strategies used by the novelist in order to highlight and explore these perceptual, intersubjective and linguistic horizons in a novel whose very structure and plot remain evasive.

mit Chaudhuri, a contemporary Indian writer, musician and scholar,
is the acclaimed author of five novels, a collection of short stories,
and poetry. He also edited an anthology of modern Indian literature, and published in 2008 a series of essays entitled Clearing a Space: Reflections On India, Literature and Culture in which he tries to define the literary lineage he belongs to. He is often considered to have departed from the magic realism and national allegory that have become the main features associated with the postRushdie novel - deviating from "the avenue in Indian writing in English that Midnight's Children opened up, along with an obsession with the monumental." (Chaudhuri 2008, 234) Chaudhuri seems to have followed another kind of path, focusing on "the raw material" of life, refuting the "spectacular" in favour of "the mundane, the everyday and the transfiguration of the mundane," (Chaudhuri 2008, 93) and he associates this tradition with Arun Kolatkar, a Bombay poet who was the first Indian poet writing in English to "devote himself utterly to the transformation and the defamiliarization of the commonplace." (Chaudhuri 2008, 94) It is significant that Chaudhuri should draw a parallel with a poet, for the notion of horizon as a structural concept often informing contemporary poetry may help us better understand his own approach to estrangement in his first novel A Strange and Sublime Address.

In his study entitled La poésie moderne et la structure d'horizon, Michel Collot refers to phenomenology philosophers (primarily Husserl and Merleau-Ponty) and defines the horizon as that which structures the experience of perception (perception of things, time, and others). He shows that perceiving the world always comes down to experiencing separation and loss. Because of the limitations of our body, our perceptions are de facto partial; we cannot see all the facets of an object; this limitation is what Husserl calls the "internal horizon" of the thing. Moreover, objects are always perceived in a context, which means they can be 
seen only in relation to other objects; this wider perspective on the object is its "external horizon." Our perception of time is similarly structured by horizons: as a transitional moment between past and future, the present is haunted by other temporalities. The past cannot be defined as a stable stock of memories, but rather as a landscape that keeps evolving as time passes. The past is thus constantly reconfigured: it is never viewed from exactly the same perspective, and it contains blank areas that may never be recaptured. The future, too, is a vast field open to endless possibilities. What of our perception of others? They, too, have their own, partial perception of the world, a perception to which the subject has no access, but which enables him or her to be aware of countless modes of virtuality, thereby giving depth to the perceiving subject's world. So, for phenomenology, horizons delineate zones of invisibility that prevent us from grasping the whole of the world, from achieving some sort of fullness or communion with it. Yet horizons are not merely obstacles: they open onto those countless possibilities. Bearing in mind this definition of the horizon, I would like to show how, for Chaudhuri, perception is an act of exploration, and writing becomes a way of probing into all these zones of invisibility - not so much to make them visible as to enhance their elusive qualities.

A Strange and Sublime Address consists of a short novel followed by nine short stories. The eponymous text is about a boy's summer holiday in Calcutta. The boy lives in Bombay, where his father works, but he regularly goes back to his uncle's house, rediscovering the Bengali family's abode and the city at large. The most striking feature is the lack of a conventional plot. The novel is an accumulation of moments or "vignettes" that focus upon the tiny events of everyday routine: morning baths, meal preparations, afternoon naps, children's games, the uncle's noisy departures for his office in a car that just will not start, the occasional visits to (or of) relatives, walks in the neighbourhood, and so on. The book records the "untidy but regular activity of the house and pavement" (20) in its own untidy but regular way. One characteristic all these fragments have in common is the writer's unflinching attention to the real. In an interview, Chaudhuri describes the real as a field of perception, and writing, he argues, can "renovate our perception of the physical world" (Ghosh 162). He thus inscribes himself in a long, vast literary tradition. I mentioned Kolatkar in my introduction, Joyce and his transfiguration of the ordinary may come to mind, just as we may associate this stance with still other writers and other times. Wonderment is, for instance, an essential characteristic of American literature, from the era of the Transcendentalists to the modernism of Ernest Hemingway and Gertrude Stein (Tanner). Emerson and Thoreau ${ }^{1}$ both advocated the need to look at the world with the innocent perspective of a child. Because he has no preconceptions, the child is open to reality's unexpected and surprising elements. Thoreau praised the "sauntering

1 Walden is a book that appears in one of the short stories that follow A Strange and Sublime Address. 
eye," able to see through the dust that "for the common eye has settled upon the universe," (Tanner 52) and sauntering is definitely one of Chaudhuri's aesthetic principles. His ten-year-old protagonist, Sandeep, is the incarnation of the writer as a young boy - Chaudhuri has acknowledged the autobiographical dimension of his maiden novel. The retrospective narration is structured around two figures, the child and the main narrator (a mature, half-ironic voice that occasionally steps forward commenting retrospectively on the development of Calcutta or giving us some cultural explanations). But more often, it is difficult to tell one perspective from the other. The adult narrator adopts the child's vision, not so much because he is interested in some kind of autobiographical investigation but because he wants to explore the child's ability to sense the world in a fresh way. Moreover, Chaudhuri's protagonist is an exiled character who needs to re-adjust his senses to the uncle's house every time he goes back. Because he is a child and a stranger, he doubly experiences the tension between the familiar and the strange, the known and the not known. This tension is heightened in the case of Sandeep, but what Chaudhuri shows is how it is inseparable from any one's perception: everyone is an outsider to reality. However, even if Chaudhuri seems to believe in the power of naïve vision to achieve a sense of wonder, there are few epiphanies in the sense of enlightening revelations. Instead, the child's perception of the familiar as "strange and sublime" only serves to increase and emphasize the ungraspable nature of reality, to reveal what in the familiar remains unknowable, in other words to rediscover the horizons that support our world and our relationship to it.

The novel opens, literally, on a threshold:

He saw the lane. Small houses, unlovely and unremarkable, stood face to face with each other. Chhotomama's house had a pomelo tree in its tiny courtyard and madhavi creepers by its windows. A boy stood clinging to the rusting iron gate, while another boy pushed it backward and forward. As he did so, the first boy travelled in a small arc through space. When the taxi stopped in front of the house, they stared at it with great dignity for a few moments, then ran off in terror, leaving the gate swinging mildly and illegally. A window opened above (it was so silent for a second that Sandeep could hear someone unlocking it) and Babla's face appeared behind the mullions. (1)

We discover the Calcutta house through the protagonist's eyes; he is not named yet - which helps the reader identify with him - and we witness the meeting of two different worlds with limits and lines that have to be crossed: the gate, the symbolic arc drawn in the air by the swinging gate, the window and its mullions. This emphasis upon liminality implicitly points to the invisible. The second paragraph corroborates this idea of a transitional moment and space:

Chhotomama and Saraswati, the maidservant, came down and helped them with their bags. Sandeep ran up the stairs with his cousins, not looking back. There was a thrilled impatience about his movements, as if he either wanted to finish or 
begin something quickly. His aunt, by contrast, stood at the head of the stairs, in a place that was half-sunlit and half shadowy, with immaculate serenity, seemingly not having moved from where she had said goodbye to him about a year ago. (1)

Here, other symbolic frontiers are drawn: between inside and outside, end and beginning, light and shadow, now and a year ago. And when the characters finally move into the house, they are associated with yet another form of invisibility: "They went up in a procession, $[\ldots]$ as if they were going up to a shrine on pilgrimage" (2). The family is symbolically moving towards the sacred, that is to say the utter Absent. Moreover, among the presents brought by Sandeep and his mother from Bombay, we find saris, folds of cloth that "broke out into a galaxy of hand-woven stars, a cosmos of streaking comets and symbolic blue horizons." (2) As the metatextual threshold of the novel, the incipit can be read as an invitation to share "symbolic horizons," to unfold (along with Sandeep) a world made of an infinity of strata.

The title of the novel is made explicit in chapter 10:

In some of Abhi's books, Sandeep found the following written on the first page:

Abhijit Das,

17 Vivekananda Road,

Calcutta (South),

West Bengal,

India,

Asia,

Earth,

The Solar System,

The Universe.

It was a strange and sublime address. (85)

The address written in the form of a short poem suggests a widening perspective, each new step opening onto an even larger sphere and provoking a vertiginous effect. It also evokes a kind of Russian doll structure in reverse. This is precisely the metaphor that keeps recurring in Collot's approach of the horizon as structure, and it is the metaphor that maybe best defines the spatial configuration developed in the book. Chaudhuri explained that even if the novel was centred on Sandeep, he was not particularly interested in the individual but more in a community of beings and in their relationship to the outside (Ghosh 164) - the outside that the narrator defines as "a bottomless being," "another blind existence," ${ }^{2}$ that is to say a horizon, constantly interacting with the enclosed space

2 "Outside, rickshawallas sang tunelessly and clapped their hands in the cold, with a small wood fire before them. Their tuneless song and their clapping hands were also a part of this other existence, this bottomless being. In the city, the winter smoke hung its giant cobwebs between the houses, or stood between each house and the darkness like a lovely, protective mosquito-net. It kept the houses warm and healed the fractures in their walls and kept out the bad dreams of the night and the memories of the day. It too was a 
of the house. The Calcutta house is repeatedly contrasted with the twenty-third floor Bombay apartment Sandeep lives in the rest of the year and in which "he was like Adam in charge of paradise, given dominion over the birds and fishes; he was too much in the foreground; he wanted a housefly's anonymity." (28) The position of visual mastery is what the child dislikes so much about the place. A year and a half later, when he is living in a bigger apartment, even higher up, he can see almost all of Bombay but "no sounds, no smells, only a pure, perpetually moving picture." (97) Seen from far above, horizons recede so much that they almost disappear. The world they delineate is reduced to a two-dimensional representation, a surface whose flatness is unsettling. When Sandeep's great-aunt remembers her childhood in Sylhet, she evokes a village similarly disconnected from the outer world:

When we were young, the world was made of small islands of consciousness. Miles separated one village, sometimes one house, from another. Letter-writing was the only means of communication - there were no telephones. A mountain or a river formed the border to our world. Our world was small, and things loomed large and astonishing for us: you wouldn't understand. (64)

In this reversed configuration, it is the absence of a background that becomes threatening. The great aunt describes life on an island without the presence of others, which may recall Robinson Crusoe's situation before the arrival of Friday. In a well-known analysis of Michel Tournier's version Vendredi ou les limbes $d u$ Pacifique, Gilles Deleuze shows how the absence of others turns Crusoe's world into a "harsh and black world" in which "the category of the possible has collapsed." Because Crusoe has only his own perspective on the world, things lose their relief, objects "rise threateningly," (Deleuze 345) and the world is deprived of its reassuring texture. The anonymity Sandeep longs for corresponds to this need for the horizons that other individuals provide. The parallel with Crusoe is made explicit in chapter 9:

For a few days, the rains fell heavily - continuous white screens blotted out landscapes and landmarks: the main road with its tramlines, its lampposts, its old medicine shop, and then the park; these melted before Sandeep's eyes, while he watched, a little amazed that he too did not melt away. [...] Saraswati returned from market with a shopping bag in her hands; insects swam away to avoid this clumsy giant. Her wet footprints printing the floor of the house were as rich with possibility as the first footprint Crusoe found on his island. (75)

To avoid the shrinking of the world to mere screens, a constant porosity between the house and its surroundings has to be maintained. Chaudhuri is a great lover of verandahs and balconies, these in-between spaces where his characters often place themselves to see life unfolding before them and to "return

part of that other blind existence that happened around the small, painful lives of human beings." (114, my italics) 
the stare of the world," (15) since balconies also frame the family themselves as they are watched by neighbours. In Chaudhuri's world, this fertile contact with the outside is not simply visual: as an accomplished musician himself, the writer pays great attention to the soundtrack of his novel. Music, songs, domestic activities, city bustle and natural sounds form a sensory halo which is yet another manifestation of the invisible and corroborates its protective dimension: for example, hearing the shrill cries of young birds behind the frosted glass of the toilet, one feels "surrounded and safe." (5) Similarly, the radio plays an important part in this structure of endless contiguities. It is what connects the household to other spheres: it links the family members to the "great fantasy world of politics and government," "soothing their minds" after they have converged towards the stifling atmosphere of the hospital waiting room after the uncle's heart attack (112); or it introduces the unexpected Australian accent of a presenter commenting on an India vs. Australia cricket match taking place on "another unwieldy mass of land floating on an ocean." (73) The invisible is also made perceptible through smells: Sandeep is aware of the existence of the basti or slum "across the railway lines" because "whiffs of excrement rose on windy days." (9) The beginning of the monsoon is announced through a rainy wind blowing in from far-off villages, groves and fields: "They sensed a presence, powerful and dangerous, though they could see nothing and no one. The nervous, toy-like city was set against the dignified advance of the clouds, as if two worlds were colliding." (72, my italics) Another line, another horizon...

The Russian doll design is found in the architectural layout of the house itself: the bedrooms face either the street or the backyard. Through windows, they open onto other houses and other bedrooms, but the interior configuration of these rooms displays a similar mise en abyme:

At one end there was a mirror and a dressing-table; the mirror imaged the room and gave it extra space. Next to it, there was a wooden clothes-horse with several horizontal bars running parallel to, and on top of, each other. One would have expected to find it in a gymnasium, but here it was - it was called an alna, and all kinds of clothes and garments hung from its ribs. A lizard lived behind it. (34)

As for the other room, it contains "another room, hidden away in the corner; three steps rose to it; it was a world within a world; a world, in fact, more richly inhabited than the sparse outer husk in which it was enclosed. [...] It was the prayer-room." (35) The children's realm is a succession of worlds that fit into each other, placed contiguously through real or symbolic lines (Venitian shutters, the bars of the alna). No wonder this playground enables them to embark on "imaginary expeditions and adventures" and "voyage daily into nowhere." (34)

The layers of invisibility that structure the children's world and give it its depth are also what accounts for the obdurate resistance the children have to face. Because of its ever changing configurations, Sandeep's world conceals as much as it reveals, and its multiple borders are not easy to cross. The others' bodies 
are often described as unknown territories, wrapped in folds of cloth that make them impossible to literally dis-cover/uncover. ${ }^{3}$ The children can only wrestle in order to explore one another's intimacy, and the metaphor of the fight implies a form of violence and a potential defeat: what Sandeep learns is that he cannot be at one with others. Others retain their opacity, their body and consciousness belonging to an inviolable sphere. The anecdote of the insect that flies into Babla's ear is quite telling in that respect: "Babla could not bear the thought of a living creature wandering inside another living creature, himself. He lived alone inside his body; he did not want to share it with an insect." (82) Even if Sandeep wants to believe in a form of communion with his cousins, he achieves only "an illusion of togetherness." (86) As soon as they go back to school and he has to spend his days alone in the house, he is confronted with the fact that he is excluded from their lives, and realizes this impossible fusion with them was precisely what fed the vividness of his own existence:

Their faces glowed with sweat and the radiance of another excitement. It gave Sandeep a sense of the other world to which they belonged and in which he played no part; it made his afternoon games with them seem small and temporary. He felt the shadowy, secret life of the holidays, the vivid underground existence during those long afternoons in the house while their parents slept calmly, slip out of his grasp. (86)

Other terrae incognitae are introduced through various metaphors. Having siblings is seen as some intangible state, out of reach too:

Sandeep, an only child, felt the shared background of brother and brother, and brother and sister, throw upon him a shade as that of the cool, expansive branches of a rooted banyan tree. He wandered in the shade, forgetting it was temporary. (3)

The remoteness of the adults' conversations is related to water imagery, to that which cannot be grasped: "Their conversation was a transparent stream that occasionally trickled into desert patches of silence." (7) Sleep is also associated with liquid elements: the uncle's "face and arms drow[n] in the black and white ocean of the newspaper, surfacing momentarily" (7); the aunt is lying on her stomach in a crab-like posture, "her arms bent as if she were swimming to the edge of a lake"; the "children sle[ep] like primeval creatures huddled on the island of the bed, close to the horizon, outwaiting the dawn." (74) In all these examples, the surface world of slumber verges on an obscure and immense depth that absorbs all sleeping consciousnesses - the land of dreams and of the unconscious. This kind of invisibility echoes the mysterious and "inconceivable" land of death that is evoked when the uncle suffers a heart-attack: "a nothingness through an invisible point." (115)

3 "[The aunt's] legs, like two romantic, indefinite paths on a mountainside, were lost in her sari's vast landscape." (21) 
What increases distance with others is the fact that the children do not share the same language. When Abhi is transferred from a Bengali-medium school to an English-medium one, he has trouble with this new language, perceived as "difficult and unapproachable." (100) Even the tutor's "natural eloquence" sounds threatened when he switches from Bengali to the "rocky terrain" of English and has to struggle against the "savage bombardment of those foreign words." (102) As for Sandeep, he is presented as "one of the innumerable language-orphans of modern India," (81) but an orphan for whom language contains other fruitful horizons. When his uncle sings old Bengali compositions, he has to ask him for the meaning of some words:

Chothomama, what does godhuli mean?

Lost in the general well-being of cleansing himself, his uncle replied patiently: 'The word go means cow, and the word dhuli means dust. In the villages, evening's the time the cowherds bring the cattle home. The herd returns, raising clouds of dust from the road. Godhuli is that hour of cow-dust. So it means dusk or evening. (53)

Through his explanations, the uncle conjures up a mental picture that Sandeep views like "a film shown from a projector." (53) Thanks to this brief moment of familiarity with the language of the other, the young boy is given access to the other's perspective on reality and discovers a new world: "It was strange how one word could contain a world within it." (54)

Sandeep feels greatly attracted to these mysterious Bengali letters which he starts interpreting as the drawings of literal characters, seeing in one of them "a fat man standing straight with his belly sticking out" and in another, the same man "scratching his back." (81) The boy faces these riddles playfully, feeling that the indecipherable language speaks to him. Sandeep's inventive interaction with Bengali exemplifies how this perpetual confrontation with invisibility rarely leaves him at a loss. Paradoxically, it is when horizons disappear that Sandeep's world shrinks to nothingness. Horizons work as spurs to his imagination, because that which cannot be fully grasped is invented. Horizons ensure what Collot calls "the fabulous dimension" of the world (Collot 1988). Note that Sandeep in Hindi means "bringer of light": he is the one who throws a different light upon reality and makes us see it differently. His perception of reality corresponds to the invention of a grotesque, baroque universe in constant metamorphosis in which the usual categories are blurred: boys are compared to "rumpled pillows," (3) testicles hang like "small, unplucked fruit," (4) babies look like "little koi fish caught from the Hooghly river," (5) a pipe reminds him of "the neck of a tired giraffe," (5) saris are wrought into "long, exhausted pythons of cloth," (6) a man suffering a heart attack is perceived like "an acrobat doing a bizarre act to impress the children," (108) with electro-cardiogram tubes growing from his hands and feet "like thin tuberous plants." (109) Chaya, the sweeper from the slum, holds a broom whose "long tail [...] reminded one of the drooping tail of some nameless, 
exotic bird" (9); when she swishes a rag, sitting on her haunches, her right arm moves "like a fin" and she suddenly acquires "an amphibian quality, half human and half of another world." (10) When Chandrina performs her dance on the balcony, her hands look like "now an absurd bird, and now like a doe's head, and now like barely visible wings" (20) Saraswati, the maid, undergoes similar transformations during a power cut:

Wavering shadows from the candle flame falling and shifting on her face gave her ordinary features a preternatural fluidity. Her cheekbones and jaw seemed to flow and change with the changing light, as if she were shedding her old face for a new one. (56)

Here, the new kind of light and the analogy might refer to Chaudhuri's recurrent technique consisting of multiplying similes and metaphors in order to produce a kind of stereoscopic effect. These stylistic figures bring together two images that, seized simultaneously, produce a three-dimensional perspective. The initial mystery of the object under scrutiny is not erased; it is replaced by other borders, with writing adding new horizons to pre-existing ones. Figures invest things and beings with another life or another identity, temporarily disclosing some of the world's multiple and hidden facets (Collot 1989, 229-249). One episode perfectly encapsulates this experience of dissolution of limits leading to the other side of reality:

[The children] roamed in a silent, self-created web of sounds, smells and colours. Once, Sandeep had woken late in the night to find Chhotomama standing at the window near the bed smoking a cigarette. The moonlight dimmed outlines and made tangible things seem intangible, and Chhotomama and the furniture in the room appeared like figures on the wrong side of a tapestry; everything seemed to be dissolving in the smoke. (102)

Since writing consists in experiencing and re-enacting fertile confrontations with horizons, it becomes a never-ending process. One of Sandeep's favourite activities is "sauntering," going for a drive in the streets of Calcutta, taking the best seat "by the open window" and feeling as if he were floating (14). He revels in looking at the facades of innumerable houses and dreaming about what they hide: "Why did these houses seem to suggest that an infinitely interesting story might be woven around them?" (57) The passage refers to the infinity that lies beyond the horizon line, an infinity whose existence is known to us, whether our senses perceive it or not. It is the bottomless well where the boy keeps quenching his thirst for sensations and illusions, where the would-be writer finds sources of inspiration (the short stories that follow the novel can be read as some of these potential stories). The text goes on:

And yet the story would never be a satisfying one, because the writer, like Sandeep, would be too caught up in jotting down the irrelevances and digressions that make up lives, and the life of a city, rather than a good story - till the reader 
would shout "Come to the point!" and there would be no point, except the girls memorising the rules of grammar, the old man in the easy-chair fanning himself, and the house with the small empty porch that was crowded, paradoxically, with many memories and possibilities. The 'real' story, with its beginning, middle, and conclusion, would never be told, because it did not exist. (58)

These lines obviously reflect the very structure of Chaudhuri's own work, which either multiplies digressions, or concentrates upon the same motifs from diverse and shifting angles. One striking feature of the novel is the confusion between two temporalities. Memories of one specific summer soon become blurred with memories of various vacations, the past turning into a vastness whose exploration is based on repeated and endless reconfiguration. Moreover, the chapters of the book follow the natural cycles of daily routine. These cyclical activities punctuate the novel's circular progression, so that the main impression is that Chaudhuri tries to recapture a tempo. Many motifs function as metatextual references to this pulsation: alternation between light and shade, heat and cool, Saraswati beating clothes on the terrace, the children playing hide-and-seek, the grown-ups "talking, falling silent, talking, falling silent, like the advance and retreat of a tide" (106). Even the breaks that first seem to interrupt this regular, repetitive flux only serve to explore other variations upon already known motifs. The end of chapter 10 , which marks the end of Sandeep's summer vacation, is a perfect reversal of the incipit: at 4 o'clock each day, with his face pressed against the mullions, Sandeep watches his cousins come back from school and welcomes them back to the "shadowy world of the holidays." (85) After a temporal ellipsis, Sandeep comes back to Calcutta a year and a half later; the city is rediscovered, in winter this time, which allows for a few changes in atmosphere, but the daily rituals are the same. With the uncle's unexpected heart attack, the children experience a new kind of grief. Yet Chhotomama's accident is clearly described as an opportunity for rebirth: after his close encounter with death, Chhotomama renews his acquaintance with friends and relatives. He "rediscovers their quirks and oddities he had known for a lifetime," (117) seeing things "he had never taken the trouble to notice before." (120) He seems to acquire the same freshness of perception as Sandeep. He starts all over again, just as the book seems to have arrived at its starting point. And the novel closes upon another motif of elusiveness:

But [the kokil] must have sensed their presence, because it interrupted its strange meal and flew off - not flew off, really, but melted, disappeared, from the material world. As they watched, a delicate shyness seemed to envelop it, and draw a veil over their eyes. (128)

As the bird withdraws, dematerializes, the children's vision is once again limited. If Chaudhuri's writing is motivated by the world's constant elusiveness, it never seems to compensate for it. Through its rhythmic play on repetitions and variations, this prose reiterates distance. In the Calcutta house, the sacred is always intimately meshed with the ordinary. Human beings and gods bear the same 
names, pictures of gods are mixed with glossy posters of film-stars or cricketers, several human episodes are seen as re-enactment of scenes from the Ramayana, and very trivial acts such as the uncle's shaving or the shaking of guavas turn into holy ceremonies. When the narrator remembers the prayer room, he evokes "the smell of sandalwood incense, the low hum of his aunt's voice, the bell ringing at the end of the ceremony, the white batashas, clean as washed pebbles, [...] the cool taste of the offerings that were distributed after the prayer." (36) This accumulation of sensory perceptions shows how sensuous the family's relationship to the divine is, the invisible thus acquiring an almost tangible quality. Beyond its cultural signification, the relationship to the sacred becomes a symbolic reminder of the horizons which inform our relationship to the world. ${ }^{4}$

Finally, another kind of horizon seems pervasive in the novel. In an essay entitled "Stories of Domicile," Chaudhuri confesses that his childhood memories of Calcutta are full of a deep "nostalgia" for the past (Clearing, 189). Calcutta's dense sensory texture, for which Sandeep feels homesick, also comes to represent a time when there was no separation between the child and his origins, a time when he existed in complete continuity with his mother's body and with his mother tongue from which he is now exiled. His exploration of perceptual horizons necessarily leads him to probe into his own personal horizons, which momentarily resurface through, for instance, episodes of involuntary memory:

A sharp aura of mustard-oil flowered, giving Sandeep's nostrils a faraway sentient pleasure - it wasn't a sweet smell, but there was a harsh unexpectedness about it he liked. It reminded him of sunlight. In Bengal, both tamarind and babies are soaked in mustard-oil, and then left upon a mat on the terrace to absorb the morning sun. (4)

Chhotomama is similarly reminded of his childhood every time he comes home and has "a small simple meal of yogurt and khoi and slices of banana, mixed together with sugar," a mixture he had first had "from his mother's fingers." (103) After his heart-attack, when he seems to have become a child again, seeing things anew, he asks himself:

If a child could remember and record its first impressions after being born, the initial sense of colours and smells and faces as person after person leaned towards its cot and peered at it, scrutinised it, if it could retell its story of its first day in the world, would it be something like this? (121)

The two characters experience a longing for a time when, in the "safe obscurity of a womb" (114) or pressed against their mother's body, they were not aware yet of the various horizons structuring their being-in-the-world. It was a time of "pure elemental feeling" (41) that has become itself a horizon. Apart from a fleeting moment when Sandeep catches his image in the mirror and sees himself

4 "The act of seeing or recognizing the real becomes a secular act full of spiritual urgency." (Chaudhuri 2008, 93) 
as a motionless self, with "jokes and rhymes in his mother-tongue upon his lips," (87) in other words as a whole self that cannot be retrieved, origins are definitely another blind spot that haunts the narrator as it does the writer. It is part of the "shadowy" raw material that Chaudhuri's first novel grapples with and celebrates.

Myriam BELLEHIGUE Université de Paris 4 - Sorbonne

\section{Works Cited}

Chaudhuri, Amit. A Strange and Sublime Address. 1991. London: Minerva, 1992.

-. Clearing a Space: Reflections on India, Literature and Culture. Witney: Peter Lang, 2008.

Collot, Michel. L'horizon fabuleux. Paris: Corti, 1988.

—. La poésie moderne et la structure d'horizon. Paris: PUF, 1989.

Deleuze, Gilles. "Michel Tournier and the World without Others." The Logic of Sense. Trans. Mark Lester. London: Continuum, 2004. 341-359.

Grosh, Sumana R. "Aalap: in Conversation with Amit Chaudhuri." The Novels of Amit Chaudhuri: An Exploration in the Alternative Tradition. Eds. Sheobhushan Shukla, and Anu Shukla. New Delhi: Sarup \& Sons, 2004.

TANner, Tony. The Reign of Wonder: Naivety and Reality in American Literature. Cambridge: Cambridge UP, 1965.

Tournier, Michel. Vendredi ou les limbes du Pacifique. 1969. Paris: Gallimard, 1996. 